\title{
Acute Effect of Different Stretching Protocols on Flexibility, Yoyo IR-1 and Repeated Sprint Ability Performance
}

\author{
Armağan KAFKAS ${ }^{1}$, Yalçın AYDIN ${ }^{1}$, Özgür EKEN ${ }^{1}$, Fahri Safa ÇINARLI'1, \\ Muhammed Emin KAFKAS ${ }^{1}$
}

${ }^{1}$ Inonu University, Faculty of Sport Sciences, Malatya, Turkey

Address Correspondence to Ö. Eken e-mail: ozgureken86@gmail.com

\begin{abstract}
The purpose of this study was to examine the acute effect of different stretching protocols on flexibility, Yo-Yo IR-1 and repeated sprint performance. The sample group of this study consists of 15 male who were doing regular exercise at least 3 years. This group performed 5 different stretching protocols on non-consecutive days. Stretching protocols were determined as follows: light jogging for only 5 minutes (NS), light jogging and static strectching (SS), light jogging and dynamic stretching (DS), light jogging and static + dynamic stretching (SDS), light jogging and dynamic + static stretching (DSS). Altough participants did not have a statistically significant effect on flexibility performance ( $p>0.05$ ), the best flexibility value was SS. Repeated sprint performance (best) values of different stretching protocols did not have statistically significant effect on repeated sprint performance (moderate, worst, decline, post fatigue index) values ( $p>0.05$ ). Repeated sprint performance was found to have a statistically significant effect on Borg values and HR mean values $(\mathrm{p}<0.05)$. It was found that Yo-Yo IR-1 has a statistically significant effect on BORG values, Yo-Yo IR-1 performance HR (pre) values, Yo-Yo IR-1 performance HR (middle) values and Yo-Yo IR-1 performance lactate values $(\mathrm{p}<0.05)$. According to the findings obtained as a result of the research; it has been observed that different stretching protocols have different effects in terms of repeated sprint, flexibility and Yo-Yo IR-1 performance parameters. Overall, these results suggest that flexibility performance may be improve after static stretching exercise.
\end{abstract}

Key words: Aerobic, Anaerobic, Flexibility, Stretching

\section{INTRODUCTION}

A single exercise session usually comprises four phases, warm-up, stretching, conditioning or sportsrelated exercise, and cool-down. The warm-up period consists of 5 to 10 minutes of low to moderate physical activity and is generally accepted and recommended to prepare the body for exhausting activity $(25,10)$. Stretching exercise, which is used as a part of pre-movement warm up, is used to increase the range of motion, reduce the flexibility resistance, provide more free movements and improved performance. The effects of stretching have been associated with both mechanical (e.g., viscoelastic deformation, plastic deformation of connective tissue) and neural (e.g., neuromuscular relaxation, modification of sensation) factor $(14,21,33)$.

The first aim of warm up is to increase the internal temperature of the muscles. the increase in muscle temperature can affect performance by causing a decrease in viscous resistance in the muscles and joints. Moreover, it is stated that the physiological and performance changes after heating can lead to permanent metabolic acidemia (acid increase) (6, 20). Hemoglobin releases approximately two times more oxygen (at $41{ }^{\circ} \mathrm{C}$ at $36^{\circ} \mathrm{C}$ ) and decomposes oxygen twice as quickly as the heat increases. The same effect is shown on the dissociation curve of myoglobin $(3,5)$. Moreover, increased temperature causes vasodilatation and increase blood flow in the muscle. Febbraio et al. (13) reported that the increase in muscle temperature increases muscle glycogenolysis, glycolysis and high energy phosphate degradation during exercise. In addition, increased muscle temperature increases the rate of transmission of nerve impulses and increases central nervous system function (CNS). The improved CNS function may have a particularly critical effect for activities requiring fast reactions and complex body movements (26).

When the literature is examined, there are different stretching protocols such as static, dynamic, combined, ballistic, proprioceptive 
neuromuscular facilitation (PNF). One of these stretching protocols is static stretching includes holding the joint at the extended position for 15 to 60 seconds until the end of the range of motion (35). Many studies have reported that static stretching does not affect short-term muscle strength, but moderate and high levels of static stretching (30-6090 seconds) reduce vertical jump, speed, and power performance. $(7,9,18,32,23)$. Ogura et al., (2007) was to investigate whether duration of static stretching could affect the maximal voluntary contraction (MVC). No static stretching condition was used as a control condition and the other groups were 2 different durations of static stretching of their hamstring muscles in the dominant leg: 30 and 60 seconds. At the end of the study they found that the hamstring flexibility was significantly increased by 30 and 60 seconds of static stretching; however, there was no significant difference between 30 and 60 seconds of static stretching conditions. The MVC was significantly lowered with 60 seconds of static stretching compared to the control and 30 seconds of the stretching conditions. However, there was no significant difference between control and 30 seconds of static stretching conditions. Therefore, it was concluded that the short duration (30 seconds) of static stretching did not have a negative effect on the muscle force production (23). Winchester et al., (2008) was to establish whether the deleterious effects of static stretching (SS) would wash out the performance enhancements obtained from the dynamic warm-up (DW). Eleven males and 11 females, who were athletes of a NCAA Division I track team, performed a DW followed with either a SS or rest (NS) condition. They finally found that time for the NS versus the SS group was significantly faster for the second $20 \mathrm{~m}$ with a time of 2.41 versus 2.38 seconds, and for the entire $40 \mathrm{~m}$ with a time of 5.6 and 6.04 versus 5.76 .04 seconds (32). It can be said that the negative effects on performance are effect of neuromuscular factors such as mechanical (changes in muscle stiffness and reflex sensitivity) and MTU (reduced motor neuron stimulation) (16). One of the preferred stretching methods is dynamic stretching. Dynamic stretching includes exercises based on jumps and various special movements (12). In some studies, it has been reported that dynamic stretching increases the speed (2), enhancing T-line agility, health ball throw, 5-step jump (22), vertical jump (17) performance. It has been reported that low to high intensity contractions such as dynamic stretching can increase strength and performance by activating nerve muscle activation $(11,15)$.

The importance of this study is there are no studies in which 5 different stretching protocols (NS, SS, DS, SS + DS, DS + SS) are used to measure flexibility, repeated sprint ability and acute effect on Yo-Yo IR-1 performance in the same study. The aim of the study is to examine the acute effect of different stretching protocols on flexibility, Yo-Yo IR-1 and repeated sprint ability. For this purpose, research hypotheses; (1) flexibility, yoyo intermittent recovery test-1 (Yo-Yo IR-1) and repeated sprint ability (RSA) performance would be affected by different stretching protocols, and (2) flexibility, YoYo IR-1 and RSA performance are expected to improve with dynamic stretching.

\section{MATERIAL AND METHOD}

\section{Participants}

The sample group of this study consists of 15 male (age: $21.80 \pm 1.37$ years, height: $1.77 \pm .032$ meter, weight: $69.09 \pm 6.65 \mathrm{~kg}$, body mass index (BMI) $21.94 \pm 2.01(\mathrm{~kg} / \mathrm{m} 2)$, body fat ratio (BFR) $10.87 \pm 3.98$ (\%) who were doing regular exercise at least 3 years. Volunteers' criteria for participation in the study are: (a) have at least 3 years of experience in sports; (b) there is no functional limitation that may affect test performance; (c) no medical condition affecting the tests; (d) the authorization form. The study was approved by the Research Ethics Committee of the institution. The criteria for exclusion from the test are any health problems during the study period, irregularity in participation in the measurements, optimum level of performance not exhibited and sloppy behaviors. All tests and training practices were performed at the same time of the day (9: 0011: 00) to avoid diurnal rhythm effect. Subjects were told to sleep for 7-8 hours before testing and participants signed a voluntary form.

\section{Experimental Design of the Study}

Anthropometric measurements of the volunteers in the study were determined. Measurements were made at Faculty of Sports Science' Sports Hall. All volunteers who agreed to participate in the study were informed in full detail of the content of their work prior to the study. Before the practice started, volunteers gave necessary information about the subject, the location and the time of the tests. After the initial warm-up (5 minutes of moderate aerobic running-jogging), stretching protocols were under the supervision of 
the leader. Volunteers were informed 24 hours before the tests that they should not use heavy exercise, alcohol, caffeine, and not to use the ingredients that are included in the ergogenic supplement. Each stretching protocol started with a low tempo (jogging) aerobics run for 5 minutes. Flexibility, repeated sprint ability, yoyo intermittent

\section{Stretching Protocols}

Figure 1. Experimental Design

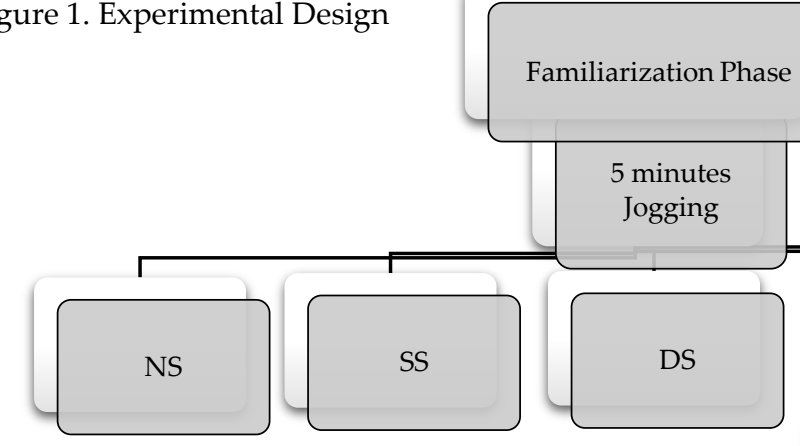

\section{No Stretching Phase (NW)}

No stretching protocol consists of 5-minute low-tempo aerobic run. After 5 minutes of lowtempo aerobic run, the flexibility of the subjects, repeated sprint performance, Yo-Yo IR-1 Table 1. Stretching Exercises

\begin{tabular}{|c|c|c|c|c|}
\hline NS & SS & DS & SS+DS & DS+SS \\
\hline \multirow{23}{*}{$\begin{array}{l}5 \text { minutes low speed } \\
\text { running }\end{array}$} & Latissimus Dorsi (Back) & High Glute Pull & Latissimus Dorsi (Back) & High Glute Pull + \\
\hline & Muscle Group & & Muscle Group + High & Latissimus Dorsi (Back) \\
\hline & & & Glute Pull & Muscle Group \\
\hline & Pectoralis Major (Chest) & Walking Lung & Pectoralis Major (Chest) & Walking Lung + \\
\hline & Muscle Group & & Muscle Group + & Pectoralis Major (Chest) \\
\hline & & & Walking Lung & Muscle Group \\
\hline & Trapezius & Light High Knees & Trapezius (Neck) & Light High Knees + \\
\hline & Muscle Group & & Muscle Group + Light & Trapezius (Neck) \\
\hline & & & High Knees & Muscle Group \\
\hline & Abdominis (Abdominal) & High Knee Pull & Abdominis (Abdominal) & High Knee Pull + \\
\hline & Muscle Group & & Muscle Group + High & Abdominis (Abdominal) \\
\hline & & & Knee Pull & Muscle Group \\
\hline & Gluteus Maximus (Hip) & Straight Leg Kick & Gluteus Maximus (Hip) & Straight Leg Kick + \\
\hline & Muscle Group & & Muscle Group + Straight & Gluteus Maximus (Hip) \\
\hline & & & Leg Kick & Muscle Group \\
\hline & Quadriceps (Upper calf) & Carioca & Quadriceps (Upper calf) & Carioka + Quadriceps \\
\hline & Muscle Group & & Muscle Group + Carioka & (Upper calf) Muscle \\
\hline & & & & Group \\
\hline & Hamstring (Back calf) & A Skip & Hamstring (Back calf) & A Skip + Hamstring \\
\hline & Muscle Group & & Muscle Group + A Skip & (Back calf) Muscle \\
\hline & & & & Group \\
\hline & Calf (Lower thigh) & B Skip & Calf (Lower thigh) & B Skip + Calf (Lower \\
\hline & Muscle Group & & Muscle Group + B Skip & thigh) Muscle Group \\
\hline
\end{tabular}

recovery test-1 performances were measured respectively after each stretching except the first stretching protocol. This study continued aproximately 20 days. Repeated sprint ability and yoyo intermittent recovery test- 1 were measured on different days. All protocols continued consecutive days.

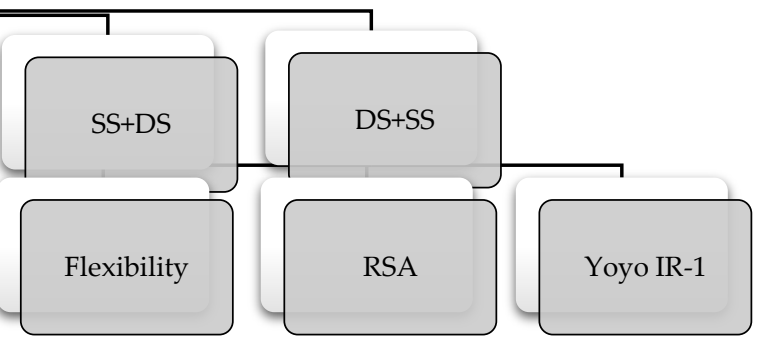

performances were measured. The maximum heart rate of the subjects was determined (29). Then, each subjects' warm up rate was calculated as $30-40 \%$ according to heart rate (19). Subjects participating in the study were run under the control of the experts. In this way, both the intensity of warm up and the warm up differences between subjects who participate in the study were removed. 


\section{Statistical Analysis}

Repeated ANOVA was used for the significance test between different stretching protocols. At the same time, bilateral comparisons of stretching protocols were analyzed by the Bonferroni corrected equivalence comparison test. The effect of five stretching protocols were analysed by an "ANOVA for Repeated Measures" (NS x SS x DS x SDS x DSS), with sphericity checked using "Mauchly's Test". The effect sizes of the different stretching protocols were explained by the values in square meters (๑2). The findings are presented as mean \pm SD (standard deviation) and an alpha level of $\mathrm{p}<0.05$ was considered statistically significant for all analyses. All data analysis was conducted using SPSS statistics computing program version 23.0 (SPSS Inc, Chicago, IL).

\section{FINDINGS}

Table 1. Demographic and Anthropometric Values of Participants

\begin{tabular}{llcccc}
\hline Parameters & N & Minimum & Maximum & Mean & $\begin{array}{c}\text { Standard } \\
\text { Deviation }\end{array}$ \\
\hline Age $($ years $)$ & 15 & 19.00 & 24.00 & 21.80 & 1.37 \\
\hline Height $(\mathrm{m})$ & 15 & 1.73 & 1.84 & 1.77 & .032 \\
\hline BM $(\mathrm{kg})$ & 15 & 58.80 & 81.70 & 68.42 & 6.81 \\
\hline BMI $\left(\mathrm{kg} / \mathrm{m}^{2}\right)$ & 15 & 19.18 & 25.79 & 21.81 & 2.00 \\
\hline BFR $(\%)$ & 15 & 6.20 & 18.00 & 10.87 & 3.98 \\
\hline LBW $(\%)$ & 15 & 55.00 & 71.30 & 60.83 & 5.13 \\
\hline RHR $(\mathrm{rpm})$ & 15 & 54 & 70 & 63.73 & 4.52 \\
\hline
\end{tabular}

BM: Body mass, BMI: Body mass index, BFR: Body fat ratio, LBW: Lean body weight, RHR: Resting heart rate)

Table 1 shows that the participants' mean age is $21.80 \pm 1.37$ years, mean height is $1.73 \pm 03$ meters, mean body mass is $68.42 \pm 6.81$, mean BMI is $21.81 \pm 2.00$, mean
BFR $10.87 \pm 3.98$, mean LBW $60.83 \pm 5.13$ and mean RHR $63.73 \pm 4.52$.

Table 2. Participants' Perceived Exertion Ratings (Borg Scale)

\begin{tabular}{llllll}
\hline Warm up Protocols & $\mathrm{N}$ & Minimum & Maximum & Mean & $\begin{array}{l}\text { Standard } \\
\text { Deviation }\end{array}$ \\
\hline NS (1) & 15 & 7 & 8 & 7.46 & .51 \\
\hline SS (2) & 15 & 8 & 12.00 & 10.13 & 1.06 \\
\hline DS (3) & 15 & 10.00 & 15.00 & 13.66 & 1.34 \\
\hline SS+DS (4) & 15 & 12.00 & 14.00 & 12.73 & .79 \\
\hline DS+SS (5) & 15 & 12.00 & 13.00 & 12.66 & .48 \\
\hline (NS = No stretching SS
\end{tabular}

(NS = No stretching, SS = Static stretching, DS = Dynamic stretching)

Table 2 shows that participants' perceived SS 10.13 \pm 1.06 , DS $13.66 \pm 1.34$, SS + DS $12.73 \pm .79$ and DS exertion ratings after stretching were found NS 7.46 $\pm .51, \quad$ + SS $12.66 \pm .48$.

Table 3. Repeated Sprint Ability Performance (RSAP (best)), RSAP (average), RSAP (worst), Sprint Performance Reduction (SPR (\%)), Fatigue Index Values

\begin{tabular}{|c|c|c|c|c|c|c|c|c|c|c|}
\hline & $\begin{array}{l}\text { Stretching } \\
\text { Protocols }\end{array}$ & RSAP (best) (p) & $\begin{array}{c}\text { RSAP } \\
\text { (average) } \\
(\mathrm{p}) \\
\end{array}$ & & $\begin{array}{l}\text { RSAP } \\
\text { (worst) }\end{array}$ & & $\begin{array}{l}\text { SPR } \\
(\%)\end{array}$ & & \multicolumn{2}{|c|}{$\begin{array}{c}\text { Fatigue } \\
\text { Index } \\
(\mathrm{sn})(\mathrm{p})\end{array}$} \\
\hline \multirow[t]{5}{*}{ RSPV } & NS (1) & $7.47 \pm .29$ & $7.74 \pm .24$ & \multirow[t]{5}{*}{.26} & $8.08 \pm .32$ & \multirow[t]{5}{*}{.47} & $3.69 \pm 1.61$ & \multirow[t]{5}{*}{.98} & .5327 & \multirow[t]{5}{*}{.90} \\
\hline & SS (2) & $7.43 \pm .25$ & $7.71 \pm .30$ & & $8.01 \pm .37$ & & $3,81 \pm 1.56$ & & .3707 & \\
\hline & DS (3) & $7.49 \pm .37$ & $7.80 \pm .37$ & & $8.21 \pm .63$ & & $3,95 \pm 1.98$ & & .5267 & \\
\hline & SS+DS (4) & $7.43 \pm .33$ & $7.72 \pm .35$ & & $8.09 \pm .49$ & & $3,91 \pm 1.48$ & & .4913 & \\
\hline & DS+SS (5) & $7.53 \pm .31$ & $7.83 \pm .35$ & & $8.12 \pm .42$ & & $3,92 \pm 1.30$ & & .5180 & \\
\hline
\end{tabular}

(RSAPV: Repeated sprint ability performance values, SPR: Sprint performance reduction)

Table 3 shows that different stretching protocols did not have statistically significant effect on RSAP (best)
( $p=0.36)$, RSAP (average) (0.26), RSAP (worst) $(0.47)$, SPR values (.98) and fatigue index values (.90). 
Table 4. Repeated Sprint Ability Performance HR, Lactate Values and Borg Values

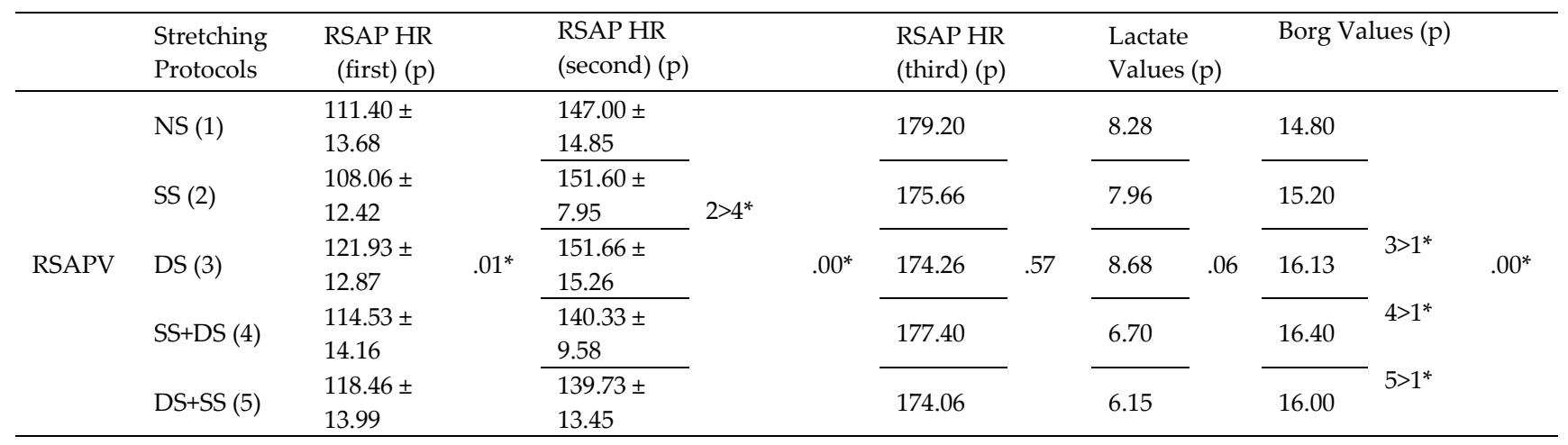

Table 4 was found that different stretching protocols have statistically significant effect on first heart rate values $(\mathrm{F}(4,56)=3.313, \mathrm{p}=.017)$, HR mean values $(\mathrm{F}$ $(4,56)=4.175, \mathrm{p}=.005)$. The third HR values didn't have statistically significant effect $(\mathrm{F}(4,56)=.736, \mathrm{p}=.572)$.

When the repeated sprint ability BORG values were examined, it was determined that different

Table 5. Yo-Yo IR1 Performance, Borg, Vo2maks and LA (son)

\begin{tabular}{|c|c|c|c|c|c|c|c|c|c|}
\hline & $\begin{array}{l}\text { Stretching } \\
\text { Protocols }\end{array}$ & $\begin{array}{l}\text { Performance } \\
\text { Values (p) }\end{array}$ & & Borg Values & & $V_{\text {O2maks }}(p)$ & & La (son) & mol) \\
\hline \multirow{5}{*}{$\begin{array}{l}\text { Yo-Yo IR1 Running } \\
\text { Performance, Borg, Vo2maks } \\
\text { and La (son) Values }\end{array}$} & NS (1) & \multicolumn{2}{|l|}{$\begin{array}{c}1442.66 \pm \\
452.41\end{array}$} & $\begin{array}{c}15.53 \pm \\
1.40\end{array}$ & \multirow{5}{*}{$0.02^{*}$} & $\begin{array}{c}48.51 \pm \\
3.80\end{array}$ & \multirow{5}{*}{0.16} & $\begin{array}{c}8.20 \pm \\
2.61\end{array}$ & \multirow{5}{*}{$.00^{*}$} \\
\hline & SS (2) & \multicolumn{2}{|l|}{$\begin{array}{c}1490.66 \pm \\
538.03\end{array}$} & $\begin{array}{c}16.00 \pm \\
1.19\end{array}$ & & $\begin{array}{c}48.91 \pm \\
4.51\end{array}$ & & $\begin{array}{c}6.59 \pm \\
2.07\end{array}$ & \\
\hline & DS (3) & $\begin{array}{l}1704 \pm \\
664.66\end{array}$ & \multirow[t]{2}{*}{0.16} & $\begin{array}{c}16.64 \pm \\
1.34\end{array}$ & & $\begin{array}{c}50.71 \pm \\
5.58\end{array}$ & & $\begin{array}{c}6.60 \pm \\
1.54\end{array}$ & \\
\hline & SS+DS (4) & $\begin{array}{l}1472 \pm \\
452.34\end{array}$ & & $\begin{array}{c}15.46 \pm \\
1.40\end{array}$ & & $\begin{array}{c}48.76 \pm \\
3.79\end{array}$ & & $6.42 \pm .85$ & \\
\hline & DS+SS (5) & $\begin{array}{c}1626.66 \pm \\
648.98\end{array}$ & & $\begin{array}{c}16.53 \pm \\
1.55\end{array}$ & & $\begin{array}{c}50.06 \pm \\
5.45\end{array}$ & & $\begin{array}{c}5.68 \pm \\
1.86\end{array}$ & \\
\hline
\end{tabular}

(Yo-Yo IR-1: Yo-Yo intermittent recovery test, LA: Lactic acid)

Table 5 was found that Yo-Yo IR-1 performance values $(\mathrm{F}(4,56)=1.954, \mathrm{p}=.16)$ and $\mathrm{VO}_{2}$ max values $(4,56)=$ $1.958, \mathrm{p}=.164)$ didn't statistically significant. Borg values

Table 6. Yo-Yo IR1 Heart Rate (HR) and Flexibility Values stretching protocols had a statistically significant effect on $\operatorname{RSAP}(\mathrm{F}(4,56)=6.725, \mathrm{p}=.005)$. According to the Bonferroni analysis results, a statistically significant difference was found between DS with NS, SS + DS and NS and DS + SS with NS warm up ( $\mathrm{p}<0.05)$.

Lactate values were not statistically significant effect on lactate values $(\mathrm{F}(4,56)=4.326, \mathrm{p}=.064)$.

\begin{tabular}{clcccc}
\hline & Stretching & HR (first) (p) & HR (second) (p) & HR (third) (p) & Flexibility (p) \\
& Protocols & & & & \\
\hline Yo-Yo IR1 Heart Rate (HR) & NS (1) & & & 0.54 & 0.36 \\
Values & SS (2) & $0.00^{*}$ & & \\
& DS (3) & & & \\
& SS+DS (4) & & & \\
& DS+SS (5) & & & \\
\hline
\end{tabular}

The HR (pre) values of the different stretching protocols before Yo-Yo IR-1 were statistically significant effect on Yo-Yo IR-1 performance HR (second) values ( $p$ $<0.05$ ) in table 6. According to the Bonferroni analysis results, a statistically significant difference was found between DS and NS, DS with SS, SS + DS with SS, DS + SS with SS and finally DS with DS + SS ( $p<0.05)$. It was found
$(\mathrm{F}(4,56)=3.130, \mathrm{p}=.02)$. and LA values of Yo-Yo IR-1 (F $(4,56)=5.969, \mathrm{p}=.000)$ are statistically significant $(\mathrm{p}<.05)$. that the different stretching protocols had a statistically significant effect on the Yo-Yo IR1performance HR (F $(4,56)=6.097, \mathrm{p}=.000)$. According to the Bonferroni analysis results, a statistically significant difference was found between NS and SS + DS, DS and SS + DS, and finally between DS + SS and SS + DS ( $p<0.05)$. 
Table 7. Flexibility Values

\begin{tabular}{|c|c|c|c|c|c|}
\hline & $\begin{array}{l}\text { Stretching } \\
\text { Protocols }\end{array}$ & Minimum & Maximum & $F$ & $\mathrm{p}$ \\
\hline \multirow{5}{*}{ Flexibility Values } & NS (1) & $27.53 \pm 7.32$ & 7.32 & \multirow[t]{5}{*}{1.107} & \multirow[t]{5}{*}{0.36} \\
\hline & SS (2) & $26.33 \pm 8.12$ & 8.12 & & \\
\hline & DS (3) & $25.86 \pm 7.50$ & 7.50 & & \\
\hline & SS+DS (4) & $26.13 \pm 7.75$ & 7.75 & & \\
\hline & DS+SS (5) & $26.60 \pm 6.28$ & 6.28 & & \\
\hline
\end{tabular}

Flexibility values didn't have statistically significant effect $(F(4,56)=.1107, p=.363)$ in table 7 .

\section{DISCUSSION}

The purpose of this study was to examine the acute effect of different stretching protocols on flexibility, Yo-Yo IR-1 and repeated sprint performance. The main findings were that no significant differences in the flexibility values variables were found between the five stretching protocols. When the flexibility performance values of the participants in terms of different stretching protocols were examined, NS: $27.53 \pm 7.32$, SS: $26.33 \pm 8.12$, DS: $25.86 \pm 7.50$, SS + DS: $26.13 \pm 7.75$ and DS + SS: $26.60 \pm 6.28$ and statistically significant effect on the obtained values $(\mathrm{F}(4,56)=.1107, \mathrm{p}=.363)$.

When the literature is examined, there are some studies about the effect of stretching protocols on flexibility performance. Unick et al. (30) examined the flexibility performance values by applying 3 different test procedures on 3 different days for 16 female basketball players. Three different stretching protocols were applied to the subjects. The first warm-up protocol included only general warm-up, while the second protocol included 15-second 3 repeated static stretching exercises for some muscle groups (quadriceps femoris, hamstring and gastrocnemius muscle groups); while the third group had 30 seconds of ballistic stretching exercises on the same muscle groups. They reported that ballistic and static stretching exercises did not affect the flexibility values of the study results. This suggests that stretching prior to competition may not negatively affect the performance of trained women. Faigenbaum et al. (11) were to compare the acute effects on youth fitness of 3 different warm-up protocols utilizing static stretching or dynamic exercise performance. Sixty children performed warm- up protocols consisted of 5 minutes of walking and 5 minutes of static stretching (SS), 10 minutes of dynamic exercise (DY), or 10 minutes of dynamic exercise plus 3 drop jumps from $15-\mathrm{cm}$ boxes (DYJ). After each warm-up protocols, subjects were tested on the vertical jump, long jump, shuttle run, and v- sit flexibility. Vertical- jump and shuttlerun performance declined significantly following SS as compared to DY and DYJ, and long-jump performance was significantly reduced following SS as compared to DYJ. Perrier et al. (24) compared the effects of a warm-up with static vs. dynamic stretching on countermovement jump (CMJ) height, reaction time, and low-back and hamstring flexibility. Flexibility was better after both static stretching (SS) and dynamic stretching (DS) compared to after no stretching, with no difference in flexibility between SS and DS. Su et al. (28) compare the acute effects of foam rolling, static stretching, and dynamic stretching used as part of warm-up on flexibility and muscle strength of knee flexion and extension. The flexibility test scores improved significantly more after foam rolling compared to static and dynamic stretching. Ahmed et al., (1) was to compare the effectiveness of modified hold-relax stretching and static stretching in improving the hamstring muscle flexibility. The subjects were randomly placed into three groups: the modified hold-relax stretching, static stretching and control groups. According to the results of this study, both the modified hold-relax stretching technique and static stretching are equally effective and there was no significant difference in improving the hamstring muscle flexibility between the two groups. Some researchers suggest that stress may cause relaxation in the tendon, thereby reducing muscle strength to the bone, reducing musculotendinous stiffness (8). Static stretching or warm up can decrease in power may be due to an increase in the length of the muscle tendon unit (27). Another theory has been suggested to be related to myogenic reflex, which indicates a decrease in natural contraction when movements in the muscles are very fast (8). 
The main findings were that different stretching protocols did not have a statistically significant effect on heart rate preliminary values in RSA performance $(\mathrm{F}(4,56)=3.313, \mathrm{p}=.017)$. RSA performance of different stretching protocols was found to have a statistically significant effect on HR mean values $(\mathrm{F}(4,56)=4.175, \mathrm{p}=.005)$. Repeated sprint performance of different stretching protocols was found to have no statistically significant effect on final HR values $(\mathrm{F}(4,56)=.736, \mathrm{p}=.572)$. When the repeated sprint performance BORG values of the participants were examined, it was determined that NS was $14.80 \pm 1.26$, SS $15.20 \pm 1.26$, DS $16.13 \pm 31.06$, SS + DS $16.40 \pm .63$ and DS + SS $16.00 \pm 92$. It was found that different warm up protocols had a statistically significant effect on the borg values in repeated sprint performance $(\mathrm{F}(4,56)=6.725, \mathrm{p}=$ .005). Repeated sprint performance of different stretching protocols was found to have no statistically significant effect on lactate values ( $F$ $(4,56)=4.326, \mathrm{p}=.064)$.

When the literature is examined, there are some studies about the effect of stretching protocols on RSA performance. Beckett et al., (4) examined the effects of static stretching during the recovery periods of field-based team sports on subsequent repeated sprint ability (RSA) and change of direction speed (CODS) performance. They found that, there was a consistent tendency for RSA times to be slower after the static stretching intervention for three performance variables. Further, sprint times is slower in the CODS-SS trial compared with the CODS-CON across all sprint variables, with a significantly slower $(p<0.05)$. In another study Tillaar et al. (29) aimed to compare the effects long and short warm-up of football players on repeated sprint performance. Ten male football players conducted two types of warm-up as long warm-up and short warm-up. RPE and heart rate were significantly higher after the long warm-up and short warm-up is as effective as a long warm-up for repeated sprints in soccer.

The main findings were that there were no statistically significant effect on Yo-Yo IR-1 performance values, VO2 max values. When the YoYo IR1 performance Borg values of the participants were examined there was found had a statistically significant effect on the Yo-Yo IR-1 performance values $(\mathrm{F}(4,56)=3.130, \mathrm{p}=.022)$, post-Yo Yo IR-1 lactate values of Yo-Yo IR-1 $(\mathrm{F}(4,56)=5.969, \mathrm{p}=$ $.000)$, Yo-Yo IR-1 performance on $\operatorname{HR}(\mathrm{F}(4,56)=$
6.097, $\mathrm{p}=.000$ ). There were also statistically significant difference was found between NS and SS + DS, DS and SS + DS, and finally between DS + SS and SS + DS ( $p<0.05)$. The HR (pre) values of the different stretching protocols before Yo-Yo IR-1 were statistically significant effect on the Yo-Yo IR-1 performance HR (second) values $(\mathrm{p}<0.05)$.

Only 1 study has focused on the effects of Yo-Yo IR1. Yanaoka et al. (31) examined the effect of halftime rewarm-up (RW) of soccer referees on Yo-Yo Intermittent Recovery Test level 1 (Yo-Yo IR-1). The Yo-Yo IR1 performance, blood glucose, free fatty acids (FFAs), triglycerides (TGs), creatine kinase (CK), and lactate concentrations, the rating of perceived exertion, mean $\mathrm{HR}$, and HRmax were analyzed. The Yo-Yo IR1 performance was higher in the halftime RW trial than in the control trial $(3,095 \pm$ 326 vs. $2,904 \pm 421 \mathrm{~m}, \mathrm{P} \leq 0.05)$.

In conclusion, repeated sprint performance was found to have a statistically significant effect on the mean HR values $(p<0.05)$. After stretching protocols Yo-Yo IR-1 performance values, HR values and YoYo IR-1 post-performance lactate values were found to have a statistically significant effect $(p<0.05)$. This study shows that coaches can suggest SS to athletes before flexibility exercise.

\section{REFERENCES}

1. Ahmed H, Iqbal A, Anwer S, Alghadir A. Effect of modified hold-relax stretching and static stretching on hamstring muscle flexibility. Journal of Physical Therapy Science, 2015; 27(2): 535-538.

2. Alikhajeh Y, Rahimi NM, Fazeli H, Rahimi RM. Differential stretching protocols during warm-up on select performance measures for elite male soccer players. Procedia-Social and Behavioral Sciences, 2012; 46 :1639-1643.

3. Barcroft J, King WOR. The effect of temperature on the dissociation curve of blood. The Journal of Physiology, 1909; 39(5): 374-384.

4. Beckett JR, Schneiker KT, Wallman KE, Dawson BT, Guelfi $\mathrm{KJ}$. Effects of static stretching on repeated sprint and change of direction performance. Medicine and Science in Sports And Exercise, 2009; 41(2): 444-450.

5. Behm DG, Kibele A. Effects of differing intensities of static stretching on jump performance. European Journal of Applied Physiology, 2007; 101(5): 587-594.

6. Bishop DJ. Warm Up II: Performance Changes Following Active Warm Up and How to Structure the Warm Up. Sports Medicine, 2003; 33(7): 483-498.

7. Chaouachi A, Castagna C, Chtara M, Brughelli M, Turki O, Galy O, Chamari K, Behm DG. Effect of warm-ups involving static or dynamic stretching on agility, sprinting, and jumping performance in trained individuals. Journal of Strength and Conditioning Research, 2010; 24(8): 2001-2011.

8. Church JB, Wiggins MS, Moode FM, Crist R. Effect of warmup and flexibility treatments on vertical jump performance. 
Journal of Strength and Conditioning Research, 2001; 15: 332 336.

9. Cramer JT, Housh TJ, Johnson GO, Weir JP, Beck TW, Coburn JW. An acute bout of static stretching does not affect maximal eccentric 1sokinetic peak torque, the joint angle at peak torque, mean power, electromyography, or mechanomyography. Journal of Orthopaedic \& Sports Physical Therapy, 2007; 37(3): 130-139.

10. Curry BS, Chengkalath D, Crouch GJ, Romance M, Manns PJ. Acute effects of dynamic stretching, static stretching, and light aerobic activity on muscular performance in women. Journal of Strength and Conditioning Research, 2009; 23(6): 1811-1819.

11. Faigenbaum AD, Bellucci M, Bernieri A, Bakker B, Hoorens K. Acute effects of different warm-up protocols on fitness performance in children. Journal of Strength and Conditioning Research, 2005; 19(2): 376-381.

12. Faigenbaum AD, Kang J, McFarland J, Bloom JM, Magnatta J, Ratamess NA, Hoffman JR. Acute effects of different warmup protocols on anaerobic performance in teenage athletes. Pediatric Exercise Science, 2006; 18(1): 64-75.

13. Febbraio MA, Carey MF, Snow RJ, Stathis CG, Hargreaves $\mathrm{M}$. Influence of elevated muscle temperature on metabolism during intense, dynamic exercise. American Journal of Physiology - Regulatory, Integrative and Comparative Physiology, 1996; 271(5): 1251-1255.

14. Franco BL, Signorelli GR, Trajano GS, Costa PB, de Oliveira CG. Acute effects of three different stretching protocols on the wingate test performance. Journal of Sports Science and Medicine, 2012; 11(1): 1-7.

15. Gelen E, Meriç B, Yıldız S. Farklı 1sınma protokollerinin sürat performansına akut etkisi. Turkiye Klinikleri Journal of Sports Sciences, 2010; 2(1): 19-25.

16. Guissard N, Duchateau J. Neural aspects of muscle stretching. Exercise and sport sciences reviews, 2006; 34: 154-158.

17. Holt BW, Lambourne K. The impact of different warm-up protocols on vertical jump performance in male collegiate athletes. The Journal of Strength and Conditioning Research, 2008; 22(1): 226-229.

18. Jason WR, Barry WS. Varying amounts of acute static stretching and its effect on vertical jump performance. The Journal of Strength and Conditioning Research, 2008; 22(3): $781-786$

19. Karvonen MJ, Kentala E, Mustala O. The effects of training on heart rate: a longitudinal study. Annales Medicinae Experimentalis et Biologiae Fenniae, 1957; 35: 307-315.

20. McGowan CJ, Pyne DB, Thompson KG, Rattray B. Evaluating warm-up strategies for elite sprint breaststroke swimming performance. International Journal of Sports Physiology and Performance, 2016; 11(7): 975-978.

21. McHugh MP, Cosgrave $\mathrm{CH}$. To stretch or not to stretch: the role of stretching in injury prevention and performance. Scandinavian Journal of Medicine Science in Sports. 2010; 20(2): 169-181.

22. McMillian DJ, Moore JH, Hatler BS, Taylor DC. Dynamic vs. static-stretching warm up: the effect on power and agility performance. The Journal of Strength and Conditioning Research, 2006; 20(3): 492-499.

23. Ogura Y, Miyahara Y, Naito H, Katamoto S, Aoki J. Duration of static stretching influences muscle force production in hamstring muscles, Journal of Strength and Conditioning Research, 2007; 21(3): 788-792.

24. Perrier ET, Pavol MJ, Hoffman MA. The acute effects of a warm-up including static or dynamic stretching on countermovement jump height, reaction time, and flexibility.
The Journal of Strength \& Conditioning Research, 2011; 25(7): 1925-1931.

25. Pescatello LS, Arena R, Riebe D, Thompson PD, eds. ACSM's Guidelines for Exercise Testing and Prescription. 9th ed. Philadelphia, PA: Lippincott Williams \& Wilkins; 2014.

26. Ross A, Leveritt $M$. Long-term metabolic and skeletal muscle adaptations to short-sprint training: implications for sprint training and tapering. Sports Medicine, 2001; 31(15): 10631082.

27. Schilling BK, Stone MH. Stretching: Acute effects on strength and power performance. Strength and Conditioning Journal, 2000; 22: 44-47.

28. Su H, Chang NJ, Wu WL, Guo LY, Chu IH. Acute effects of foam rolling, static stretching, and dynamic stretching during warm-ups on muscular flexibility and strength in young adults. Journal of Sport Rehabilitation, 2017; 26(6): 469-477.

29. Tanaka H, Monahan KD, Seals DR. Age-predicted maximal heart rate revisited. Journal of the American College of Cardiology, 2001; 37: 153-156.

30. Unick J, Keifer HS, Cheesman W, Feeney A. (2005). The acute effects of static and ballistic stretching on vertical jump performance in trained women. Journal of Strength and Conditioning Research, 2005; 19 (1): 206-212.

31. Van den Tillaar R, Von Heimburg E. Comparison of two types of warm-up upon repeated-sprint performance in experienced soccer players. Journal Of Strength and Conditioning Research, 2016; 30(8): 2258-2265.

32. Winchester JB, Nelson AG, Landin D, Young MA, Schexnayder IC. Static stretching impairs sprint performance in collegiate track and field athletes. Journal of Strength and Conditioning Research, 2008; 22(1): 13-19.

33. Weppler $\mathrm{CH}$, Magnusson SP. Increasing muscle extensibility: a matter of increasing length or modifying sensation? Physical Therapy in Sport, 2010; 90(3): 438-449.

34. Yanaoka T, Yamagami J, Kidokoro T, Kashiwabara K, Miyashita M. Halftime rewarm-up with intermittent exercise improves the subsequent exercise performance of soccer referees. The Journal of Strength and Conditioning Research, 32(1), 211-216.

35. Young WB, Behm DG. Used during a warm-up for strength and power activities? The Journal of Strength and Conditioning Research, 2002; 24(6): 33-37. 